\title{
Research on the Damage Assessment of Carbon/Epoxy Composite Laminates at Different Impact Energy
}

\author{
Aying Zhang ${ }^{1,2, *}$, Haibao $\mathrm{Lu}^{1}$ \\ ${ }^{1}$ Harbin Institute of Technology, Harbin 150001, People's Republic of China \\ ${ }^{2}$ Harbin University, Harbin 150086, People's Republic of China
}

\begin{abstract}
The influence of the impact energy on the impact damage of the carbon fiber fabric reinforced epoxy composites laminates was investigated. Impact tests on the carbon/epoxy composite laminates with the size of $600 \mathrm{~mm} \times 700 \mathrm{~mm}$ were conducted with different the impact energy levels from $5 \mathrm{~J}$ to $65 \mathrm{~J}$ at the room temperature, respectively. After the impact test, the impact crater depth and the matrix length was measured on the tested specimens. The calipers and three-dimensional microscope was used to characterize the damage after impact tests. The experimental results show that the impact damage tends to be more severe as impact energy increases. The crack length of the carbon/epoxy composite laminates increases linearly with the increasing impact energy.
\end{abstract}

\section{Introduction}

Fiber-reinforced laminated composites are widely used in load-bearing aircraft structures on account of their light weight, high specific strength and stiffness, good corrosion resistance, super fatigue strength limit and reduced number of parts counts [1,2]. Despite performing better than conventional metallic materials, one of the main drawbacks of composite laminates is that they show a large variation of properties mainly in strength due to their in homogeneity [3]. The impact damages of the composite laminates include delamination, fiber breakage and matrix cracking [4,5]. Those impacts induce widespread subsurface delamination damage and consequently reduce the strength of the composite body structure [6-8]. The main defect of composite laminates is their susceptibility to impact damage. When the composite structures are loaded, the impact damage behaves as a discontinuity and may result in premature structural failure at loads well below design strength of the structures [9-11].

A series of impact tests were carried out on the woven-fabric carbon/epoxy laminates to generate the impact response of the composite laminates for the composite fuel tank. In this study, the impact test was performed on the carbon/epoxy laminates to evaluate the characteristics for the impact damage and the effects of the impact energy on the impact damage. The CFRP laminates with the size of $600 \mathrm{~mm} \times 700 \mathrm{~mm}$ were subjected to impact loading at the energy levels from $5 \mathrm{~J}$ to $65 \mathrm{~J}$ at the room temperature. After the impact tests had concluded, the impact damage including the crater depth and the crack length were measured on the tested specimens.

\section{Experimental}

\subsection{Materials}

The composite laminates were fabricated from commercially available (Hexcel Composites Ltd.) carbon fiber/epoxy matrix pre-impregnated tapes. The composite laminates were made of T800 carbon fibers pre- impregnated with Hexcel X850 epoxy resin (fiber volume fraction of $65 \pm 2 \%$ ). The impact damage of CFRP laminates was investigated.

As shown in Figure 1, the carbon fiber/epoxy matrix laminates $(600 \mathrm{~mm} \times 700 \mathrm{~mm}$ ) were made by the hand lay-up and cured in an autoclave system. The sequence of CFRP laminates was $[+45 /-45 / 0 /-45 / 90 /+45 / 0 / 0 /-$ $45 / 0 / 90 / 0 /+45 / 0 / 90 / 0 /+45 / 0 / 0 /-45 / 0 /+45 / 0 / 0 /-45]_{s}$.

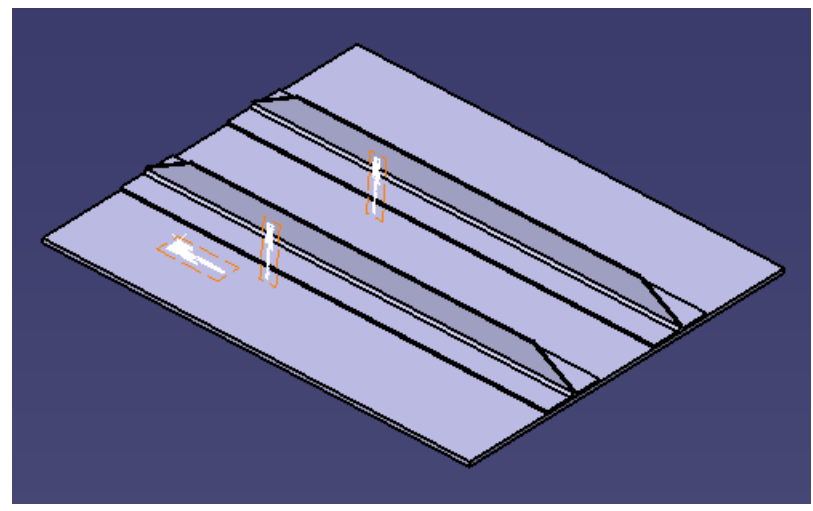

Figure 1. Image of specimens.

\subsection{Impact test}

Impact tests were performed using a drop-weight system, DYNATUP model JLW-100 with a pair of adjustable rebound catchers to prevent multiple impacts. Impact was given to the specimen by the drop-weight with a hemispherical impactor of $6.35 \mathrm{~mm}$ in radius. The mass of the impactor was $5 \mathrm{~kg}$, The impact energy increase from $5 \mathrm{~J}$ to $65 \mathrm{~J}$ and the increment is $5 \mathrm{~J}$.

\subsection{Impact damage test}

Impact damage consists of internal damage such as delamination, matrix cracking and fiber failure, which cannot be discerned by visual inspections. The impact damage takes form of crater and longitudinal and transverse cracks. The calipers with testing accuracy of $0.02 \mathrm{~mm}$ were used to measure the cracks length. The 
three-dimensional microscope (KEYENCE VHX1000) was used to characterize the damage after impact tests.

\section{Results and discussion}

\subsection{Impact cracks length}

The impacted damage areas were visually inspected on the impacted and back surfaces. No apparent damage was observed on either side at the impact energy of $5 \mathrm{~J}$.

Figure 2 shows that the crack lengths increase linearly with the increasing impact energy. For the specimen, no apparent impact cracks were observed on either side at the impact energy of $5 \mathrm{~J}$ to $35 \mathrm{~J}$.

As the impact energy increased to $40 \mathrm{~J}$, the matrix cracks took place in the vicinity of the impact point while no matrix cracks were detected in the opposite impact side of the specimens.

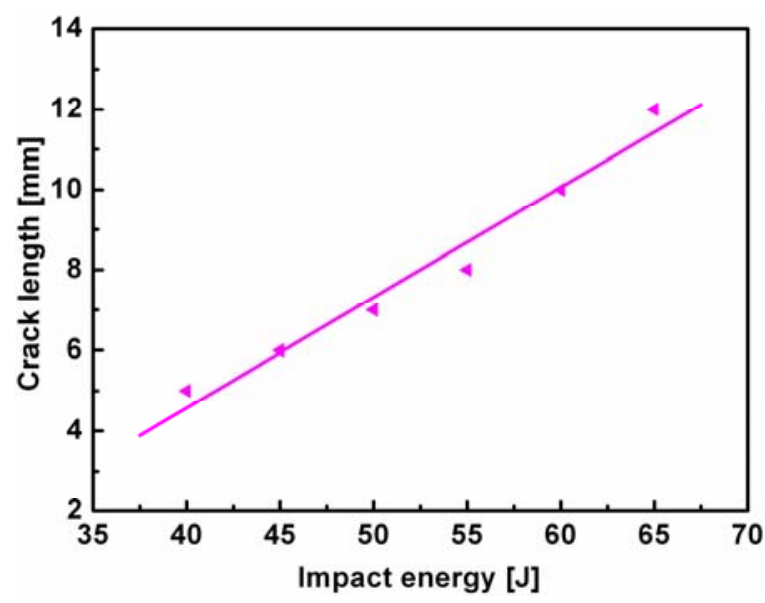

Figure 2. The crack length of CFRP laminates versus impact energy.

As shown in Table 1, the number and length of impacted specimens increase with the increasing impact energy. Table 1 shows that when the impact energy increased to $40 \mathrm{~J}$, two impacted cracks could be inspected and the length of crack reached to $5 \mathrm{~mm}$.

When the impact energy increased to 65J, five impacted cracks could be inspected and the length of crack reached to $12 \mathrm{~mm}$.

Table 1. The number and length of crack.

\begin{tabular}{|c|c|c|}
\hline $\begin{array}{c}\text { Impact energy } \\
(\mathbf{J})\end{array}$ & Number of crack & $\begin{array}{c}\text { Length of crack } \\
(\mathbf{m m})\end{array}$ \\
\hline 40 & 2 & 5 \\
\hline 45 & 2 & 6 \\
\hline 50 & 2 & 7 \\
\hline 55 & 4 & 8 \\
\hline 60 & 4 & 8 \\
\hline 65 & 5 & 12 \\
\hline
\end{tabular}

\subsection{Impact cracks depth}

\subsubsection{Impact crater at the energy of $55 \mathrm{~J}$}

Figure 3 shows that the number and length of the matrix cracks of the impacted specimens on the impacted side at the energy of $55 \mathrm{~J}$.
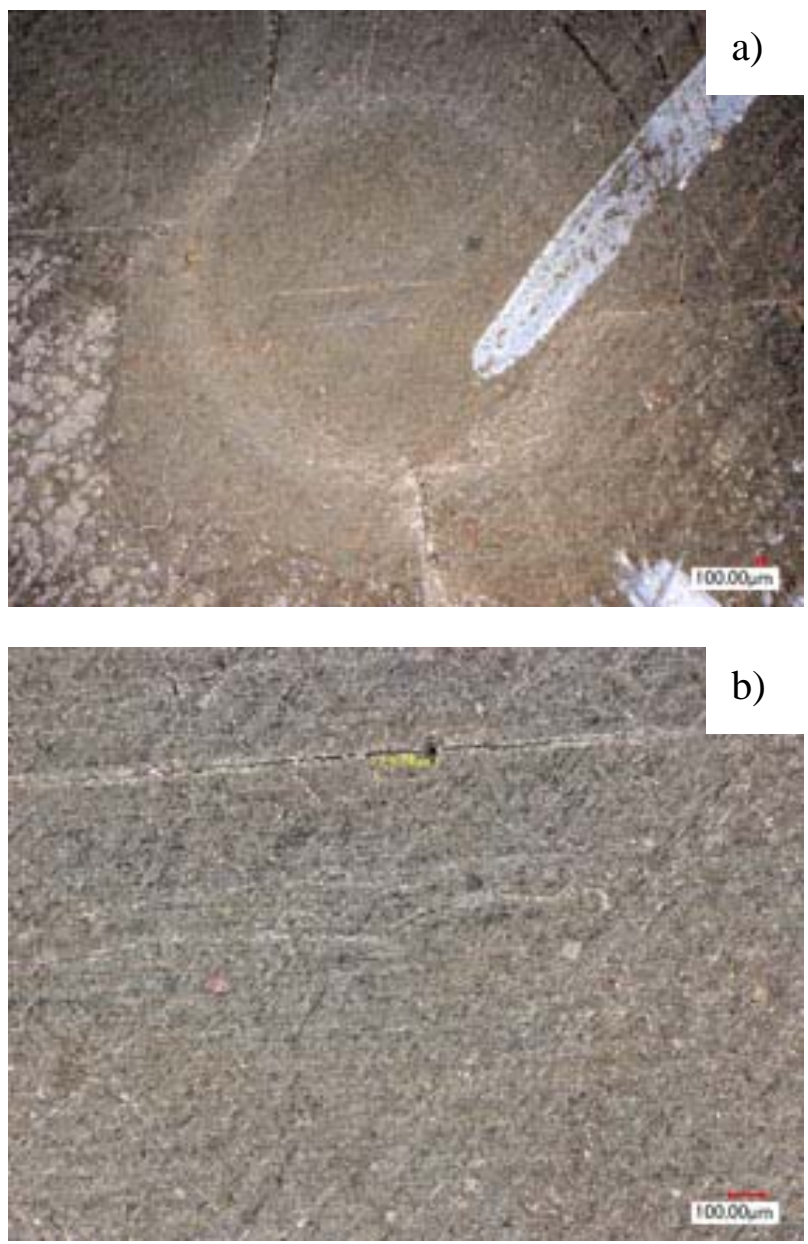

Figure 3. Images of the impact crater at the energy of $55 \mathrm{~J}$. a) the impacted side, b) the opposite side.

\subsubsection{Impact crater at the energy of $60 \mathrm{~J}$}

Figure 4 shows that the number and length of the matrix cracks on the impacted side at the energy of $60 \mathrm{~J}$. 


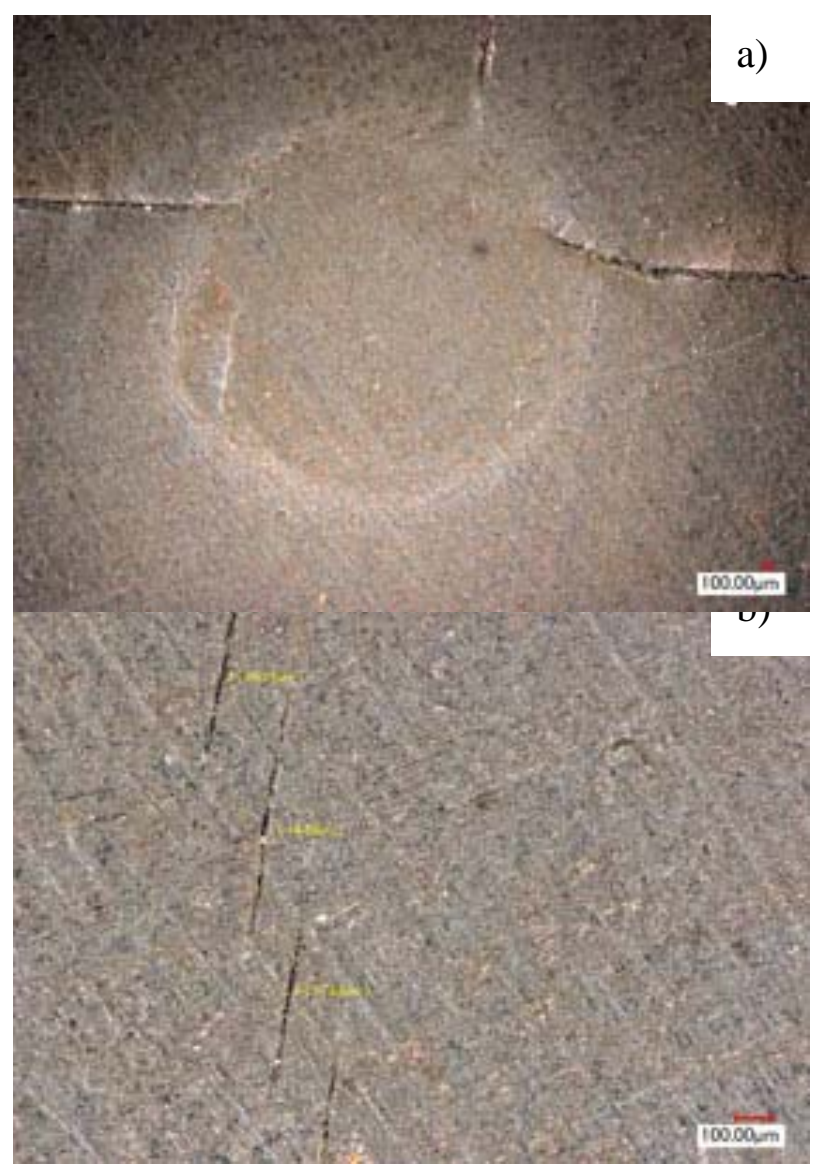

Figure 4. Images of the impact crater at the energy of $60 \mathrm{~J}$. a) the impacted side, b) the opposite side.

\subsubsection{Impact crater at the energy of $65 \mathrm{~J}$}

Figure 5 shows that the number and length of the matrix cracks on the impacted side at the energy of $65 \mathrm{~J}$.

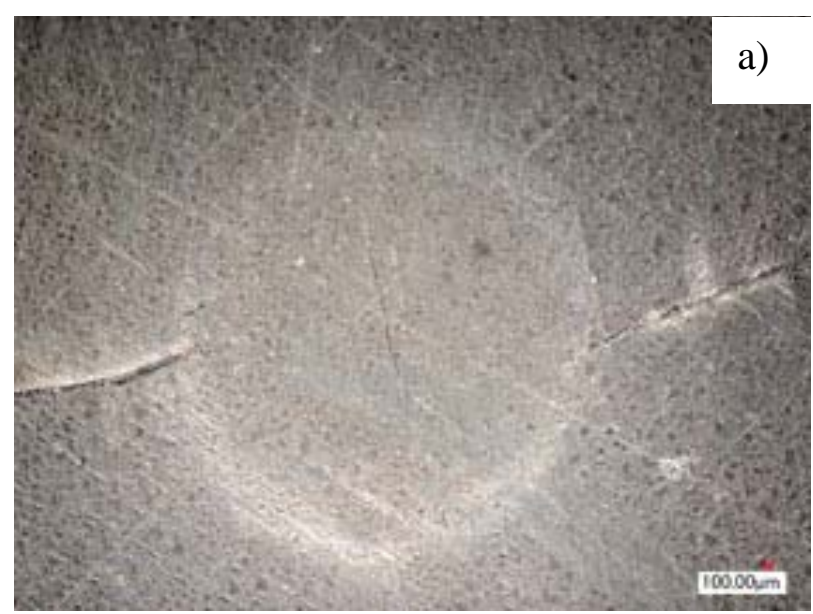

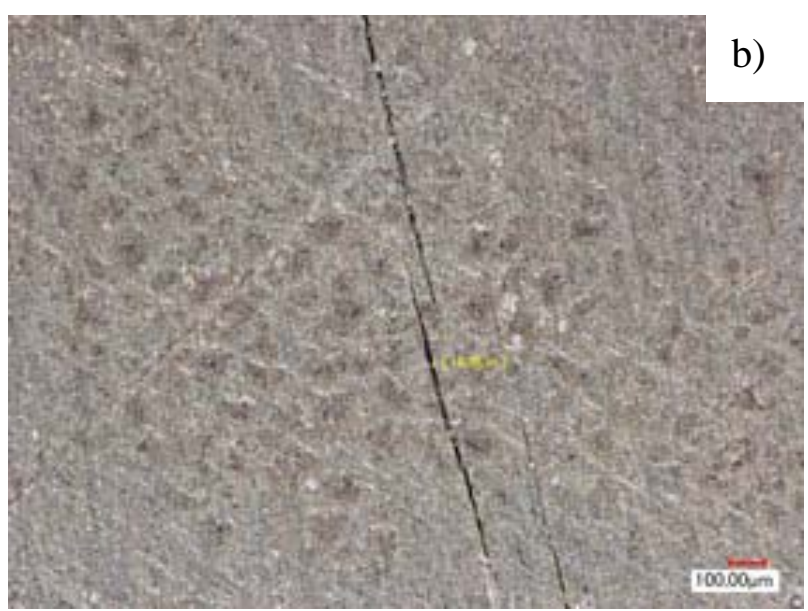

Figure 5. Images of the impact crater at the energy of $65 \mathrm{~J}$. a) the impacted side, b) the opposite side.

Figure 3 to Figure 5 shows that the number and length of the matrix cracks on the impacted side increased as impact energy levels increased. The impact damage of the opposite side tends to be more severe as impact energy increases.

\subsubsection{Impact crater rebound value with time}

Figure 6 shows the crater rebound value with time. The crater depth was inspected on the impacted surface at $0 \mathrm{~h}$, 1 h, 3 h, 6 h, 24 h, 48 h and 168 h, respectively.

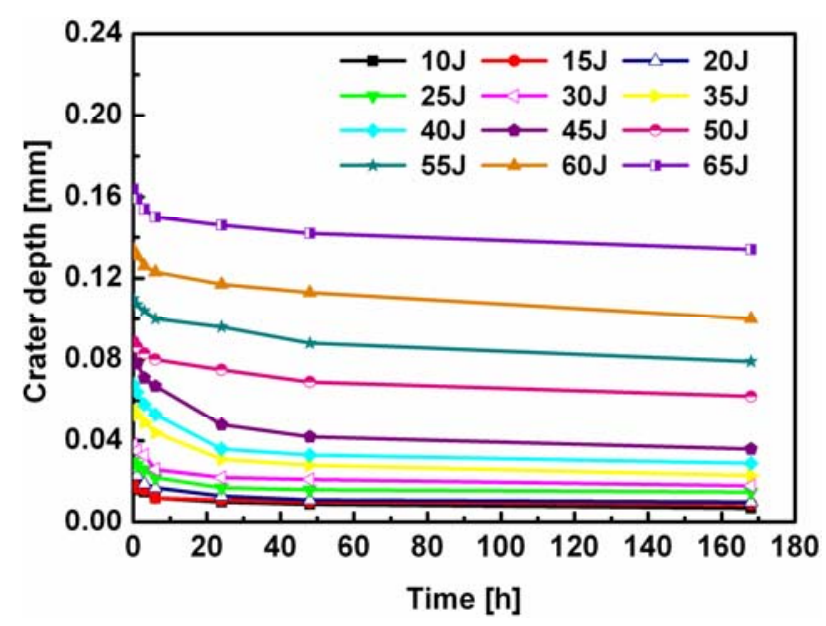

Figure 6. Curve of the crater depth of specimens with time

As shown in Figure 6, the crater depth curves of the impacted specimens at different energy levels seem to have two stages. Figure 6 shows that the crater depth decreases significantly before approximately $24 \mathrm{~h}$ in the first stage. Then, a progressive reduction of the crater depth is observed in the second stage.

\subsection{Impact damage}

The damaged zones of CFRP laminates at different impact energies were characterized by three-dimensional microscope as shown in Figure 7 to Figure 9. 
Figure 7 and Figure 8 shows damaged zones of the specimens at the impact energies of $55 \mathrm{~J}$ and $60 \mathrm{~J}$.

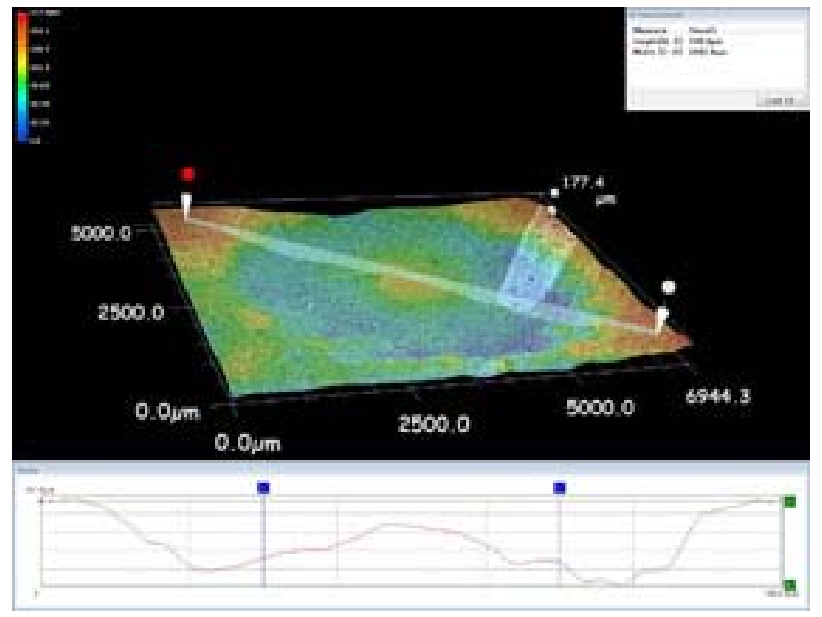

Figure 7. Impact damage of specimen at the energy of $55 \mathrm{~J}$.

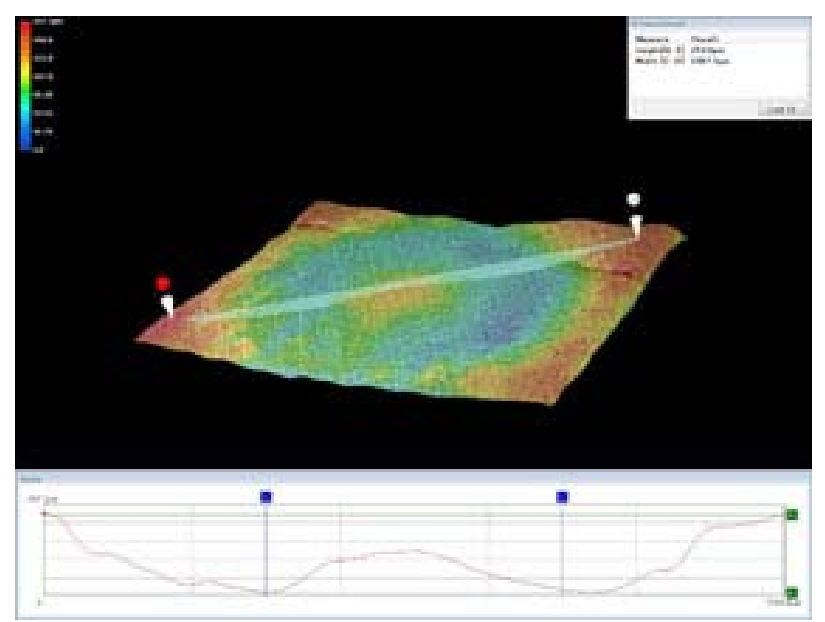

Figure 8. Impact damage of specimen at the energy of $60 \mathrm{~J}$.

Figure 9 shows damaged zones of the impacted specimen at the impact energies of $65 \mathrm{~J}$.

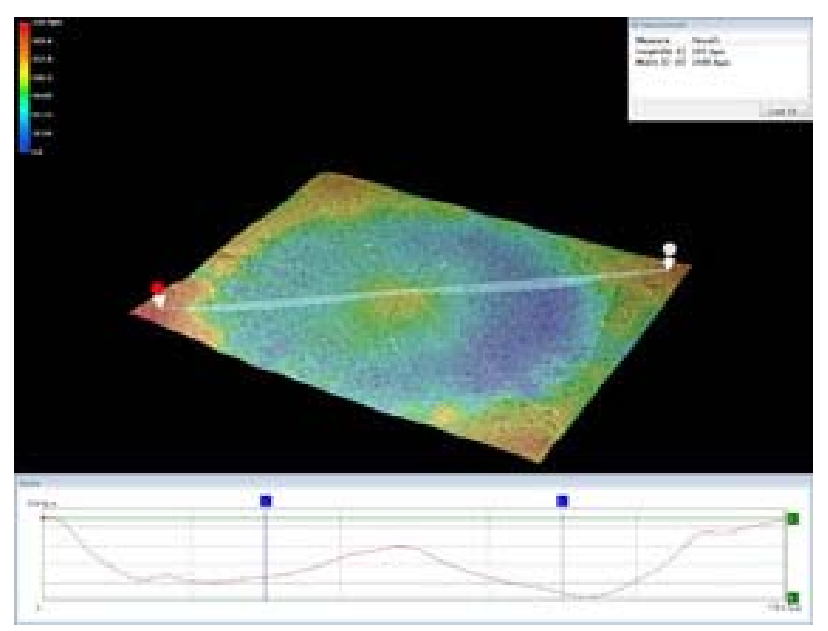

Figure 9. Impact damage of specimen at the energy of 65J.
Figure 7 to Figure 9 shows that the impact area and crater depth of the specimens increase with increasing impact energy.

\section{Conclusions}

The influence of the impact energy on the impact damage of the carbon fiber fabric reinforced epoxy composites laminates was evaluated. Impact tests on the Carbon/Epoxy composite laminates of the size of 600 $\mathrm{mm} \times 700 \mathrm{~mm}$ were conducted with different the impact energy levels from $5 \mathrm{~J}$ to $65 \mathrm{~J}$ at the room temperature, respectively. After the impact test, the impact crater depth and matrix length was measured on the tested specimens. Through systematic investigation, three conclusions were drawn.

The crack lengths of the Carbon/Epoxy composite laminates increase linearly with the increasing impact energy.

The impact damage of CFRP laminates tends to be more severe as impact energy increases.

The impact area and the crater depth of specimens increase with increasing impact energy.

\section{Acknowledgements}

This work was financially supported by China Postdoctoral Science Foundation (Grant No. 2014M551238) and Heilongjiang Postdoctoral Science Foundation (Grant No. LBH-Z13096). This work was also financially supported by Heilongjiang Natural Science Foundation (Grant No. E201454).

\section{References}

[1] G. Minak, P. Morelli, A. Zucchelli. Compos. Sci. Technol. 69, 1358 (2009)

[2] P. N. B. Reis, J. A. M. Ferreira and et al: Compos. Sci. Technol. 60, 154 (2009)

[3] C. Santiuste, S. Sanchez-Saez, and E. Barbero: Compos Struct. 92, 25 (2010)

[4] T. R. Andrew, B. Richard and W. H. Giles: Int J Solids Struct. 45, 4349 (2008)

[5] K.W. Kang, H.S. Kim, et al. Mater Sci Eng. A483484, 333 (2008)

[6] M. L. Costa, M. C. Rezende, S. F. M. Almeida. J Compos. Mater. 39, 1943 (2005)

[7] K. H. Im, C. S. Cha, et al. Compos Part B. 32, 669(2001)

[8] S.A. Baeurle, A. Hotta, A.A. Gusev. Polymer. 47, 6243 (2006)

[9] A.R. Chambers, J.S. Earl, et al. Int J Fatigue. 28, 1389 (2006)

[10]F. Awaja, B. Arhatari, et al. Polym Degrad Stab. 94, 814 (2009)

[11]P.D. Puglia, M.A. Sheikh, D.R. Hayhurstb. Compos Part A. 35, 223 (2004) 